\title{
Influence of the titanium dental implants surfaces on viability of osteoblast-like cells
}

Alves FF, Oliveira NK ${ }^{\star}$, Marques MM, Deboni MCZ, Naclério-Homem MG Faculty of Denstitry - USP - University of Sao Paulo, Sao Paulo, BRAZIL Department of Maxillofacial Surgery

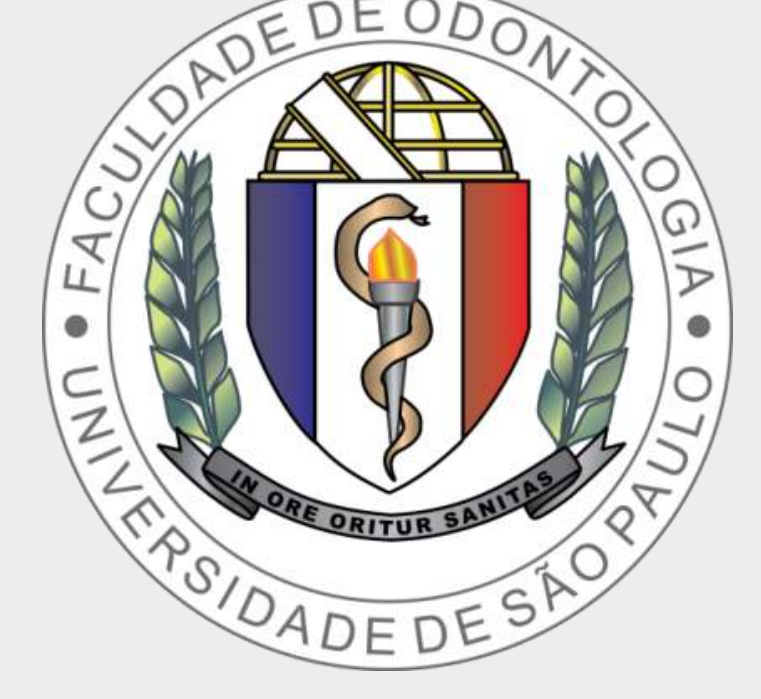

\section{Abstract}

Four different dental implant surfaces were tested: sandblasted with acid-etched and calcium phosphates coating (AAMB); double acid-etched (SW); acidetched (MP), and anodized (VA). Osteoblast-like cells were seeded on the top of these implant surfaces. The viability of the cells was assessed at 24,48 and 72 hours later, using the MTT assay. The distribution and morphology of the cells was observed in scanning during whole experimental times in all surfaces, except by the double acid-etched surface. At 72 hours after plating cells grown on the top of the SW surface presented the lowest viability Most surface area was covered by the cells, which exhibited the classical osteoblast-like morphology in all surfaces, except in the SW surface. The double acid-etching treatment of dental implant surfaces creates morphology that impairs the intimate interface with cultured osteoblast-like cells.

\section{Background and Aim}

Osseointegration was defined as a structural and functional connection between a living tissue-bone load. One of the current challenges osseointegration is the development of a titanium implant surface that could accelerate or itmprove osseointegration process. Strategies to achieve this issue include adjustments in surface characteristics like roughness, chemical composition, superficial energy and hydrophobicity that can affect cell energy and hydrophobicity that can affect cel
behavior in bone-implant interface. Manufactures offer different surfaces of dental implants to enhance the possibility of choice for a great variety of clinica situations. The purpose is that one surface topography and/or composition can be more appropriate than other in cases where there is poor bone density, like posterior maxilla region or when a systemic condition is present affecting bone metabolism like diabetes or osteoporosis. It is well known that bone cells adhesion, differentiation and proliferation on the titanium surface are extremely important for osseointegration process (9). The type of the surface can alter the interface between the cells with the implant surface. Thus, the aim of this study was to compare the viability of osteoblast-like cells grown on the top of four different dental implant surfaces.

\section{Methods and Materials}

Dental implants

Seventy-six commercially available dental implant of the same size $(3.75 \times 10 \mathrm{~mm})$ and different surfaces were kindly provided by the suppliers:

Intra-lock ${ }^{\mathrm{TM}}$, nano surface ossean ${ }^{\mathrm{TM}}$ (AAMB; Boca Raton, FL, USA), surface treated by acid-etching micro blasted with CaP coating;

SIN $^{\circledR}$, active surface (SW; SIN System of Implants, Sao Paulo, SP, Brazil) treated by double acidetching;

Conexão ${ }^{\circledR}$ Surface Porous (MP; Conexão ${ }^{\circledR}$ Sistemas, Arujá, SP, Brazil) treated by acid etching.

Actives Vulcano (VA; Conexão ${ }^{\circledR}$ Sistemas) anodized.

Cell viability

The dental implants were placed on the bottom of 12-well culture plates, immobilized by biocompatible plastic device and covered by cell culture medium. Then, $5 \times 10^{4}$ Osteoblastic cells were seeded on each type of implant. Cultures were incubated for 24, 48 and 72 hours. Cell viability was determined by MTT assay (Fig. A and B).
Arrangement of implants in culture plates

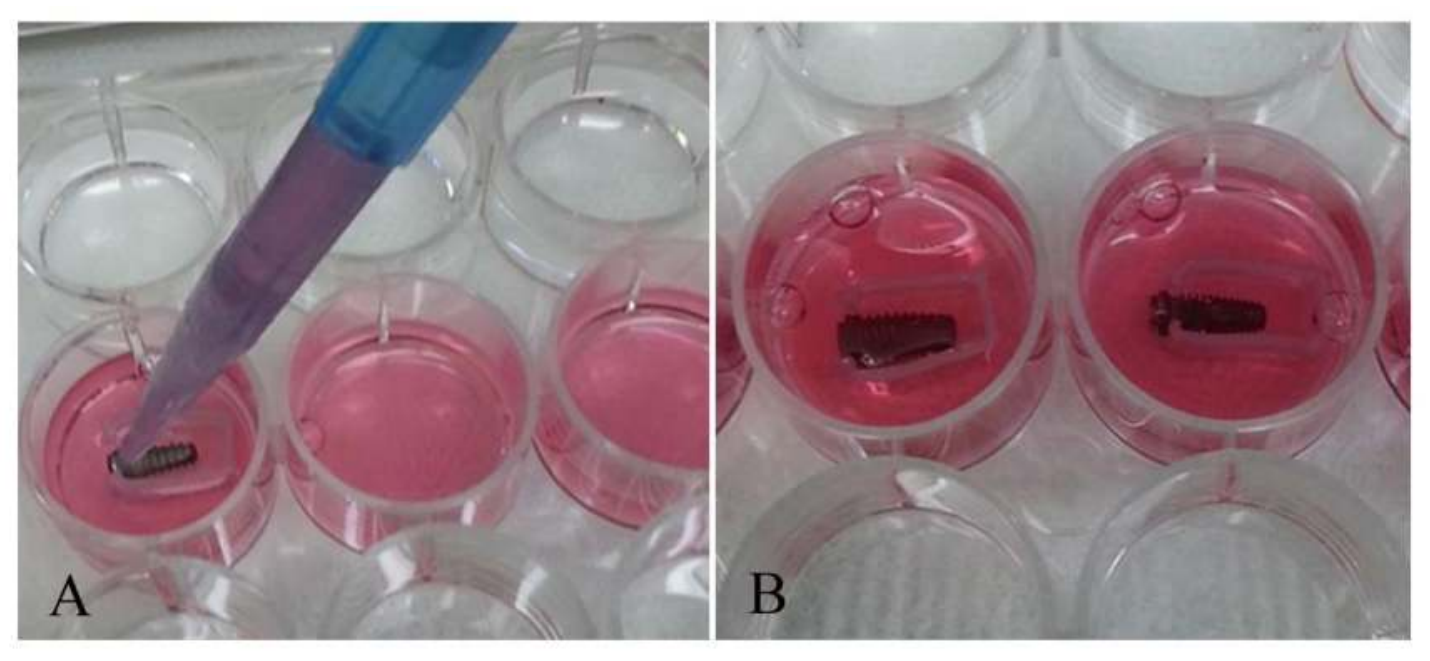

Scanning electron microscopy

\section{For a qualitative analysis of the topography of the different implant surfaces and the
interface with the attached cells}

1. $5 \times 10^{4}$ Osteoblast cells per implant were seeded on the top of each type of implant.

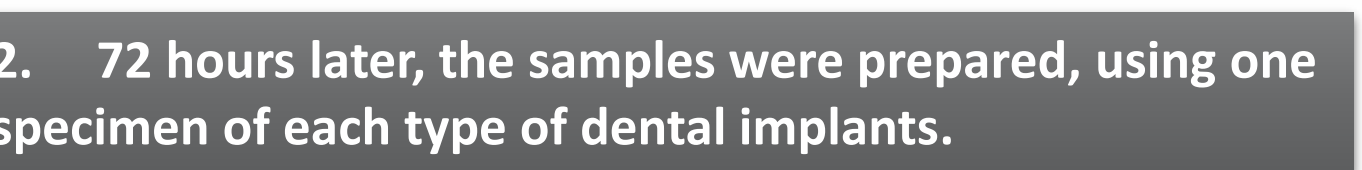

3. Representative electronmicrographies of the surfaces of the implants were obtained in a scanning electron microscope (SEM) field emission operated at $20 \mathrm{kV}$, at

Statistical analysis

Mean values and standard deviation obtained for viability by the Tukey's test was performed to evaluate differences between the groups. $p$ value $<0.05$ was considered significant.

\section{Results}

The figure below shows the growth curves of Osteoblast cells attached to all dental implant surfaces during the experimental time. The cell viability of all groups was similar until $48 \mathrm{~h}$. At $72 \mathrm{~h}$ the cells grown on the top of the SW implantation presented the smallest viability $(p=0.03)$. The remaining groups presented similar cell viability.

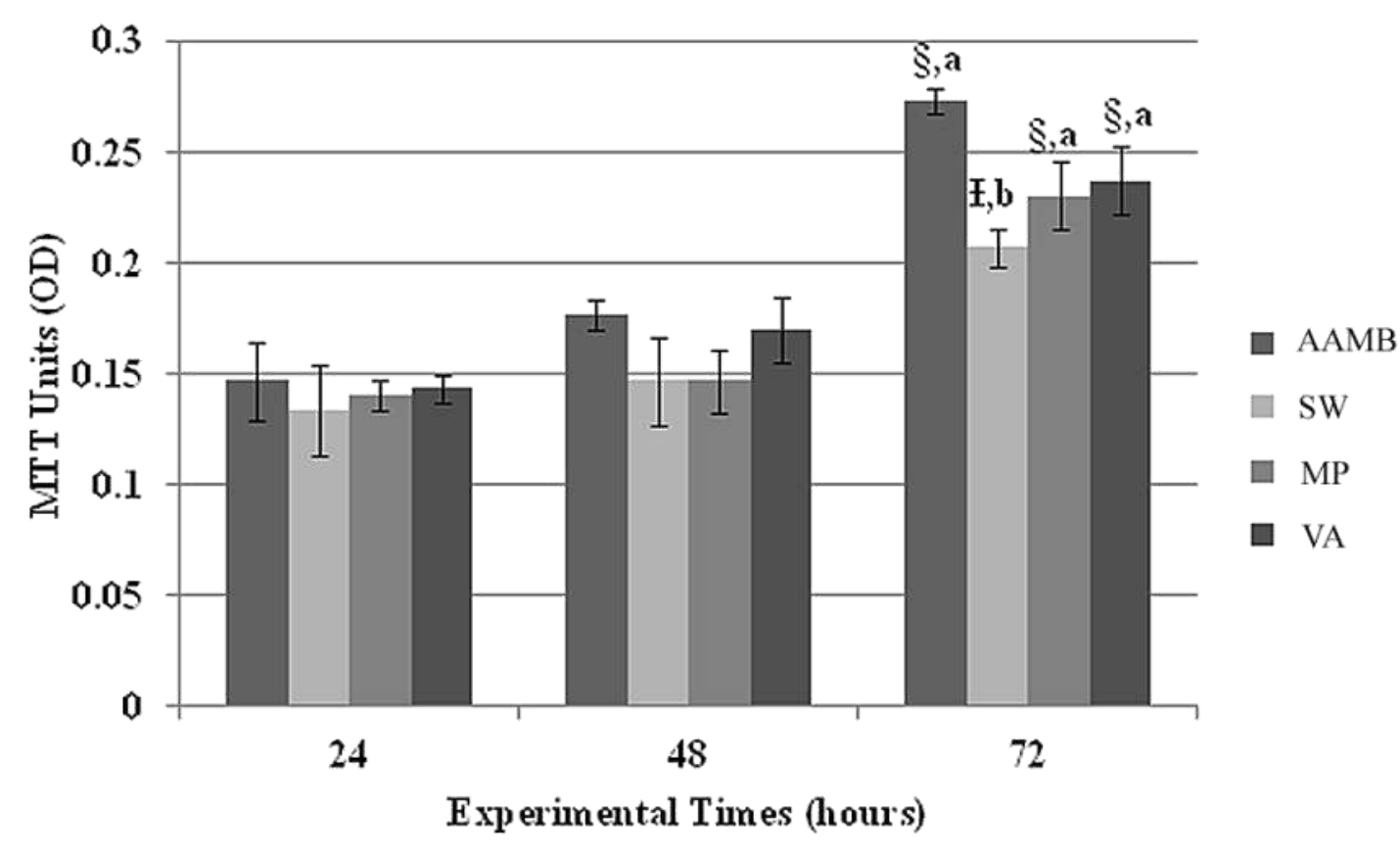

AAMB - Fig. A :Sandblasting and etching with CaP coating implants exhibited roughened surface with a homogeneous distribution. Cells covered most surface area. Osteoblast cells attached to the AAMB surface presented the classical morphology of osteoblast-like cells. They were flattened and polygonal displaying numerous filipodia into the interior of the surface roughness (Fig. B).

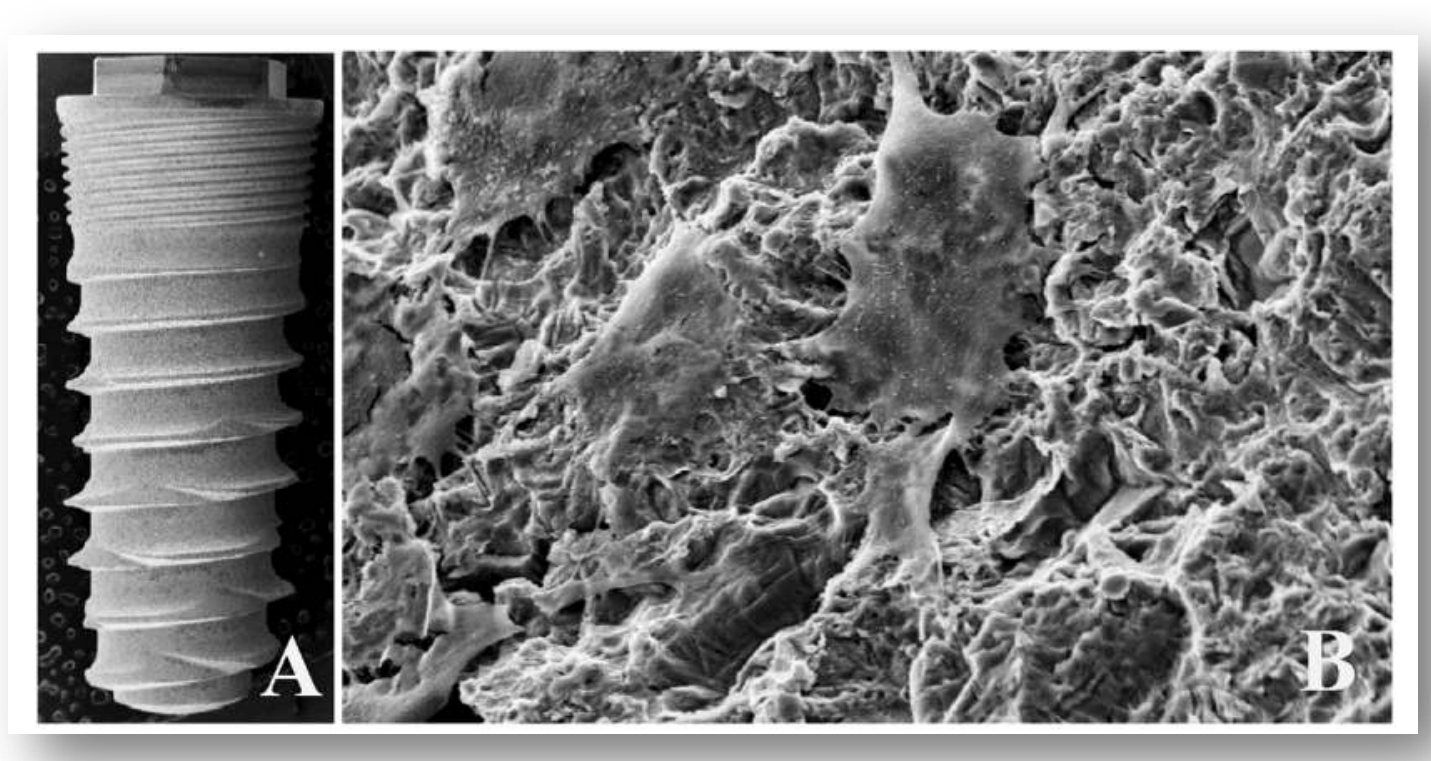

The double acid etching (SW; Fig. C) exhibited a porous roughened surface represented by irregular indentations with sharp cutting edges. Large portions of the surface were exposed with no attached cells. The cells present a more fusiform aspect with no filipodia and with no intimate interface with the implant surface (Fig. D).

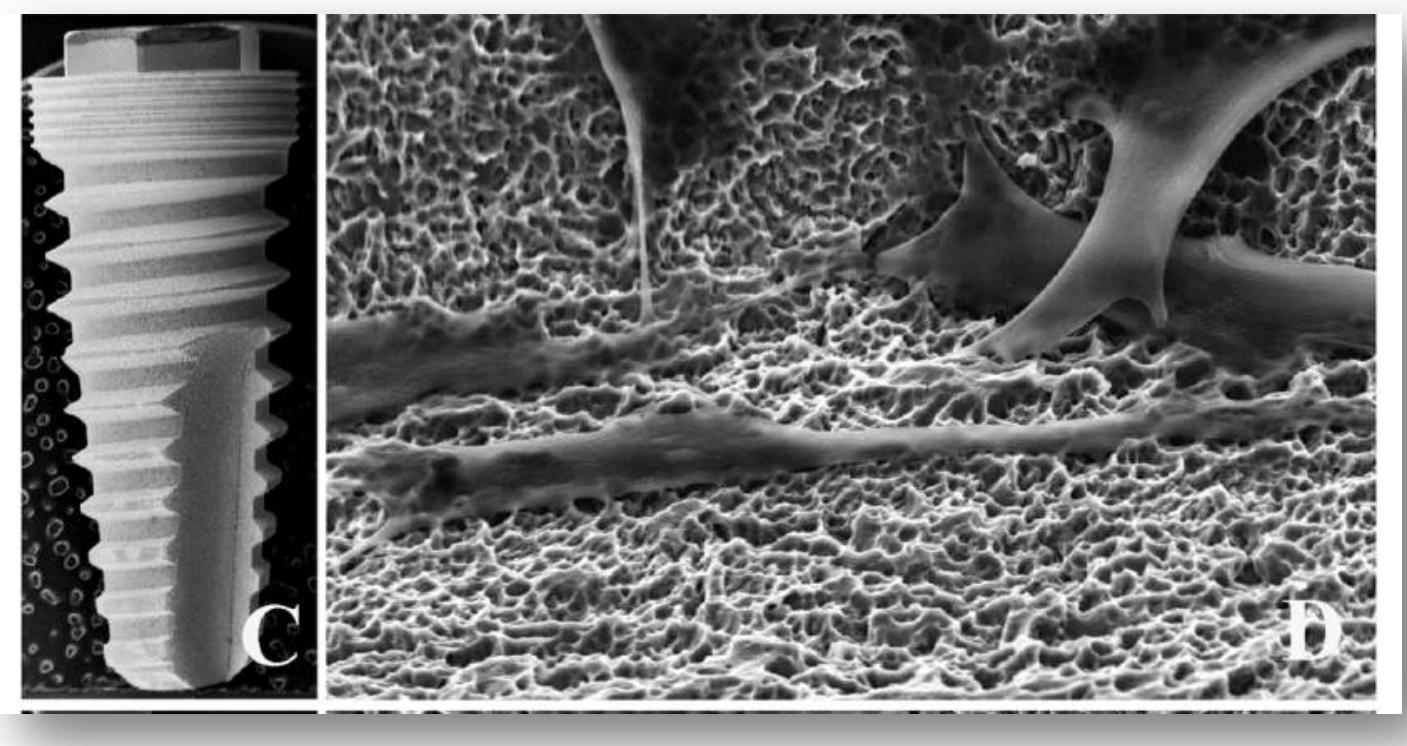

The MP implant (Fig. E) presented a porous surface represented by micro-holes homogeneously distributed. Tike cells with intimate contact with the surface (Fig. F).
lint

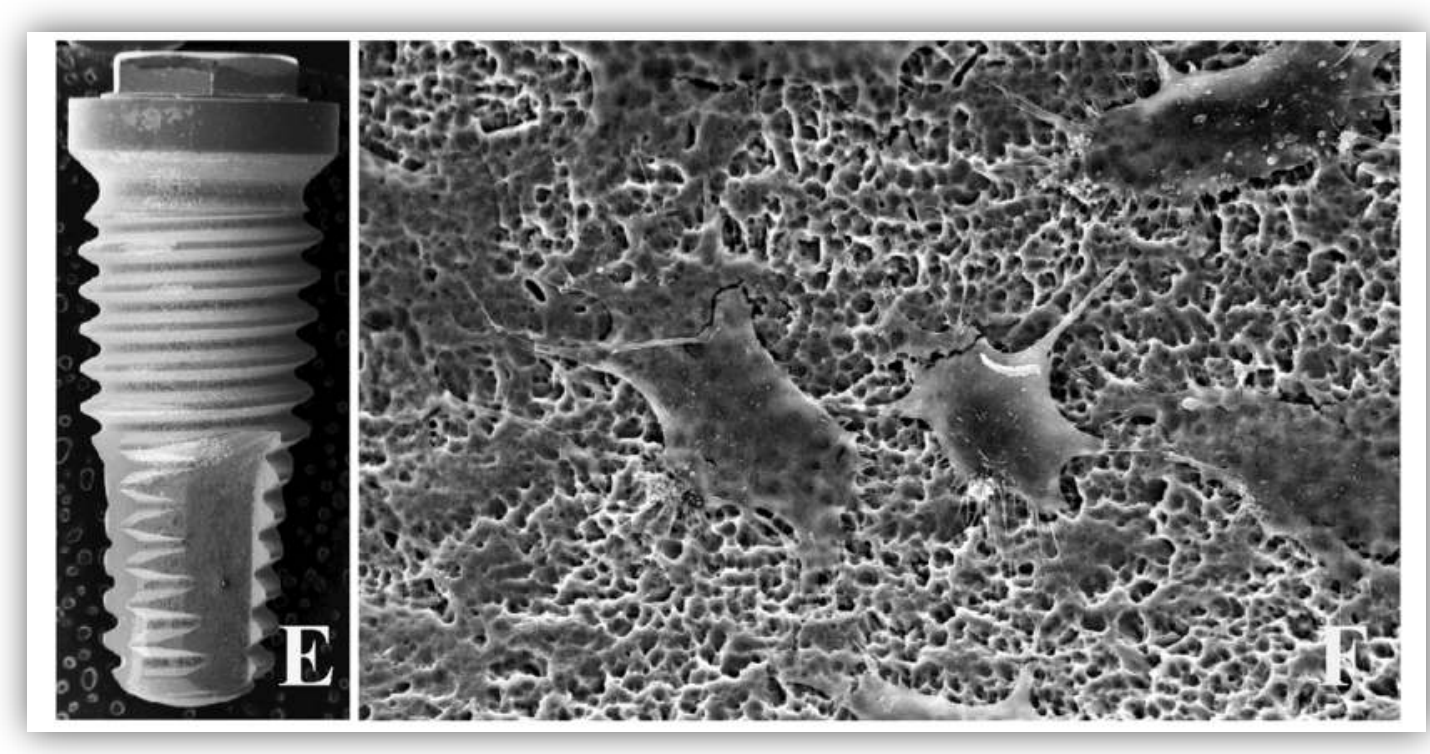

Implants of anodic oxidation surface (VA; Fig. G) presented small porous indentations exhibiting peaks with rounded edges. Most surface area was covered with flattened polygonal cells in close contact with the surface (Fig. $\mathrm{H})$.

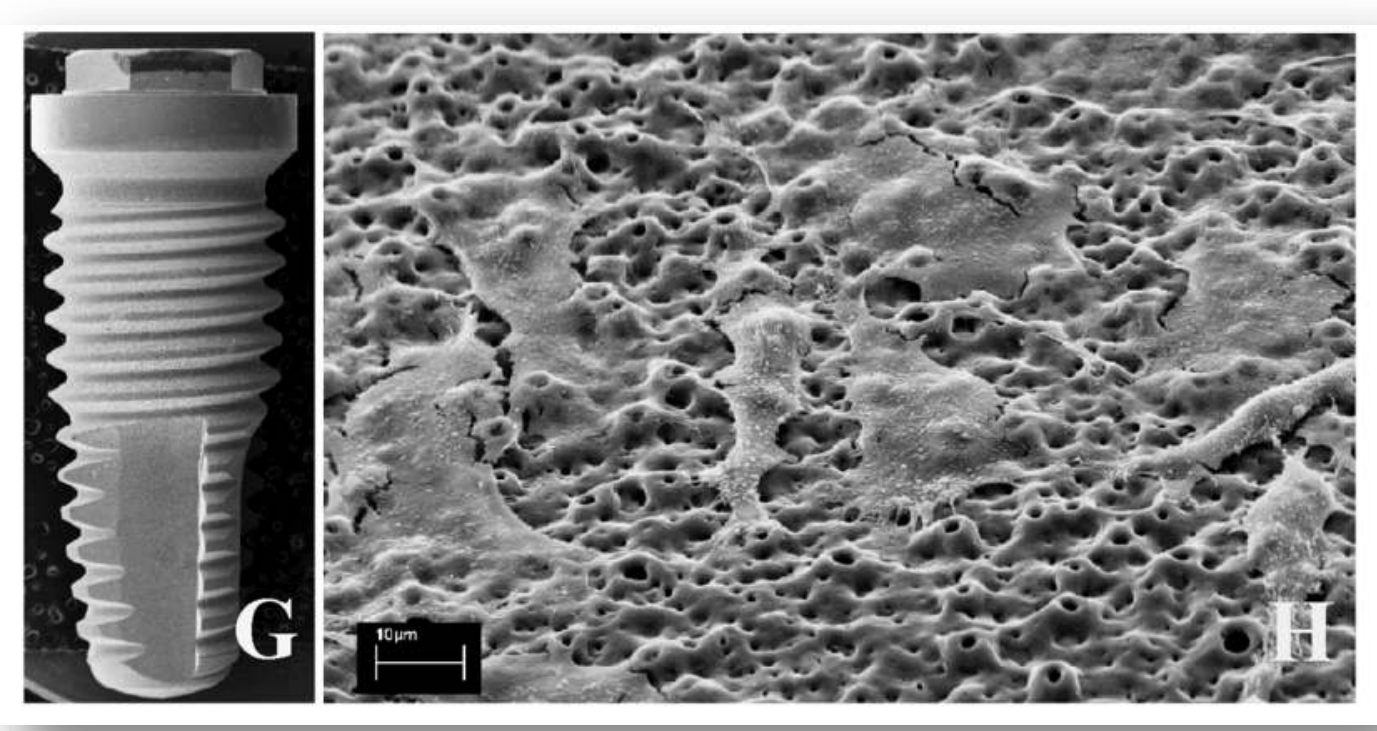

\section{Conclusions}

The double acid-etching treatment of denta implant surfaces creates a morphology that impairs the intimate interface with cultured osteoblast-like cells. This could represent a negative impact in the osseointegration process in vivo.

\section{References}

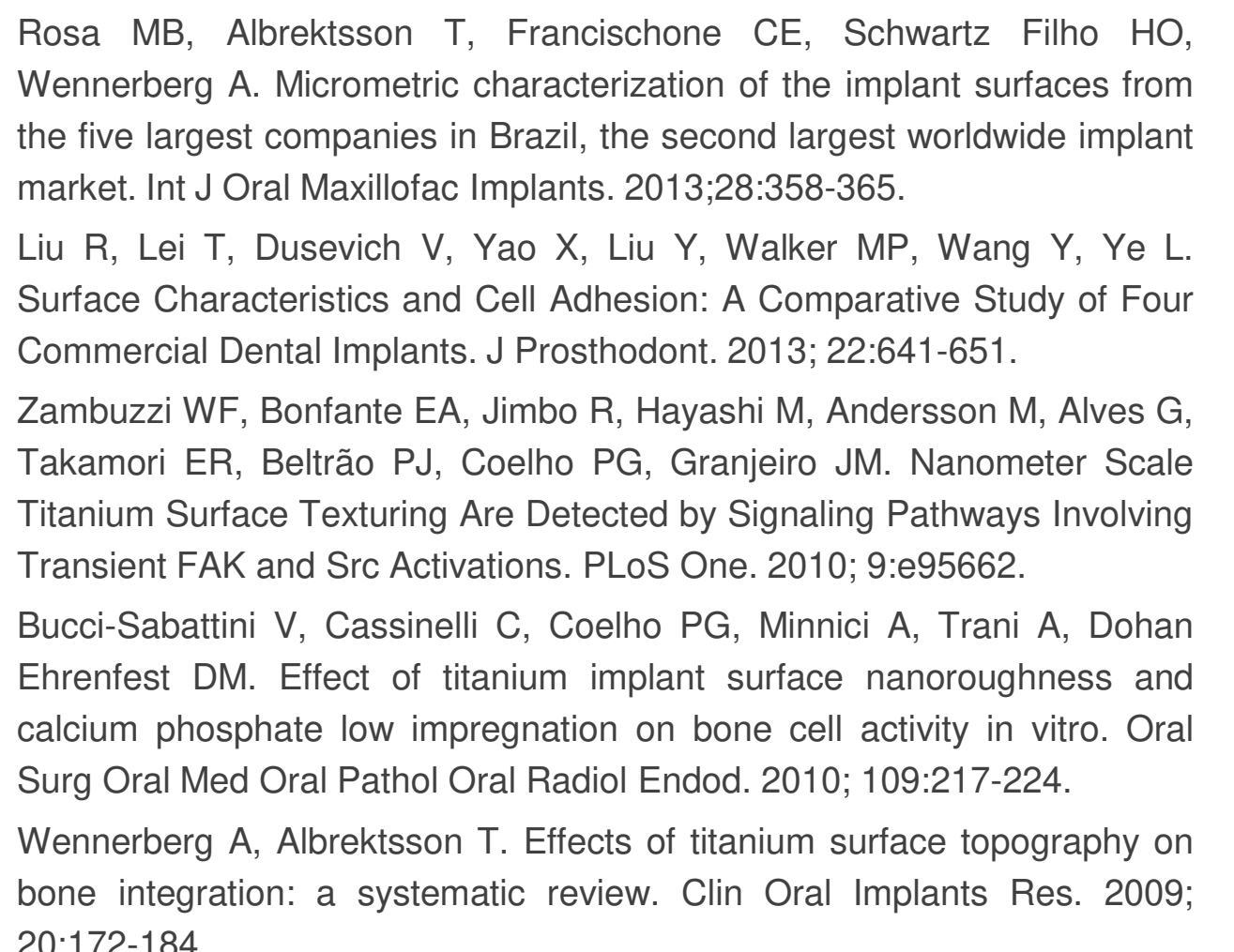

